\title{
Aeroacoustic Validation of Installed Low Noise Propulsion for NASA's N+2 Supersonic Airliner
}

\author{
James Bridges \\ NASA Glenn Research Center
}

AIAA SciTech 08 January 2018

Supported by

NASA Advanced Air Vehicles Program/Commercial Supersonic Technology Project PIV data by Mark P. Wernet, Phased array data by Gary G. Podboy 
- NASA Supersonic Airport Noise Tech Challenge:

"Deliver design tools and innovative concepts for integrated supersonic propulsion systems with noise levels of 10 EPNdB less than FAR 36 Chapter 4, demonstrated in ground test."

- Final design concepts were based on low-boom Lockheed-Martin conceptual vehicle, with propulsion systems designed by NASA Glenn.

- System studies* looked at multiple engine and nozzle types.

- Variable Cycle Engines (VCE) and Mixed Flow TurboFans (MFTF)

- Four nozzle types downselected for test.

- Capture impact of installation.

- Validate noise levels to see if Tech Challenge met.

- Validate predictive tools for nozzle and installation effects.

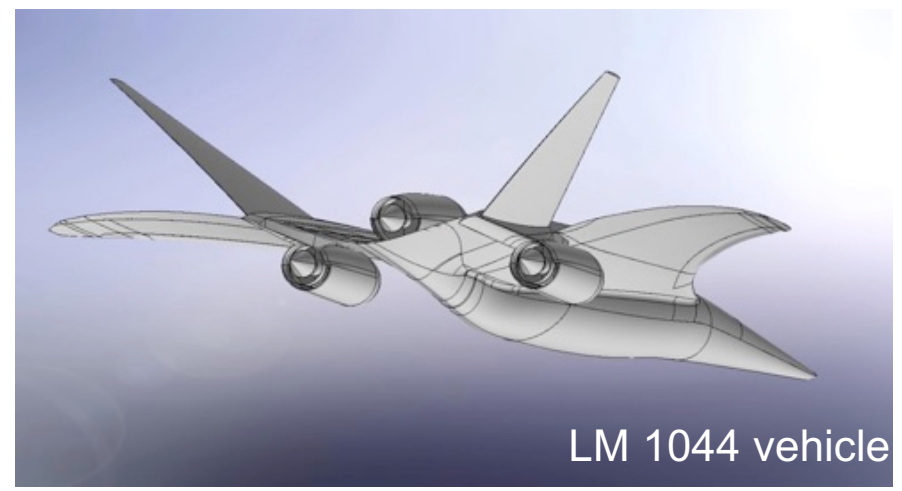

*Bridges, J., Brown, C. A., and Seidel, J. A., "NASA's Pursuit of Low-Noise Propulsion for Low-Boom Commercial Supersonic Vehicles" SciTech18 (AA-03) 15:00 Monday afternoon 


\section{Innovative Concepts}

- Jet noise is dominant noise component for supersonic aircraft.

- Variable Cycle Engine (VCE)

- Method explored: variable tip fan (third stream).

- Compare against state of art dual-stream mixed flow turbofan (MFTF)

- Innovative nozzle concepts for VCE

- With three propulsion streams from engine, find best nozzle for noise, range.

- Impact of propulsion installation

- Benefit of shielding/Penalty of reflection

- Impact of operation-Programmed (Throttle) Lapse Rate (PLR)

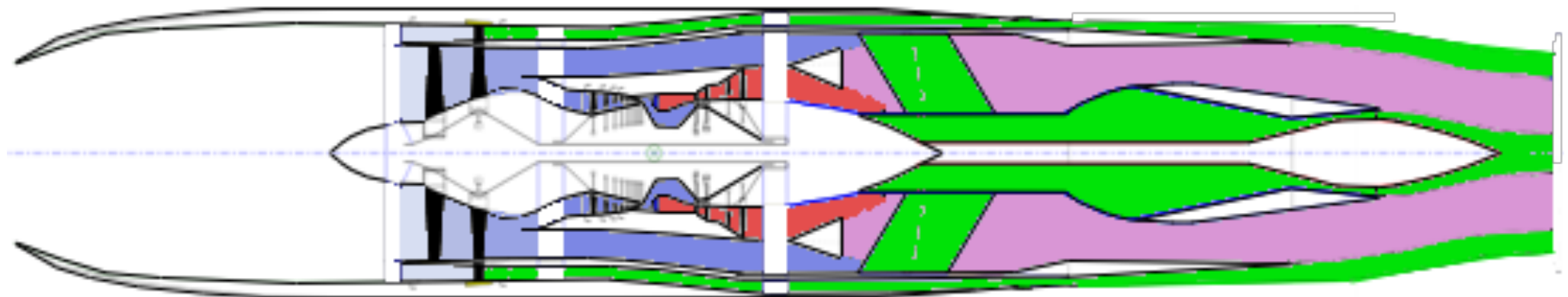

VCE with split-stream nozzle 


\section{Engine Designs for Validation}

- Many engine designs were coupled with LM1044 vehicle. Empirical noise prediction codes were used with aero and engine codes to predict mission range and takeoff noise.

- Designs that maximize range while meeting noise goal were selected for validation.

- Also selected designs requiring PLR to validate design tool sensitivities.

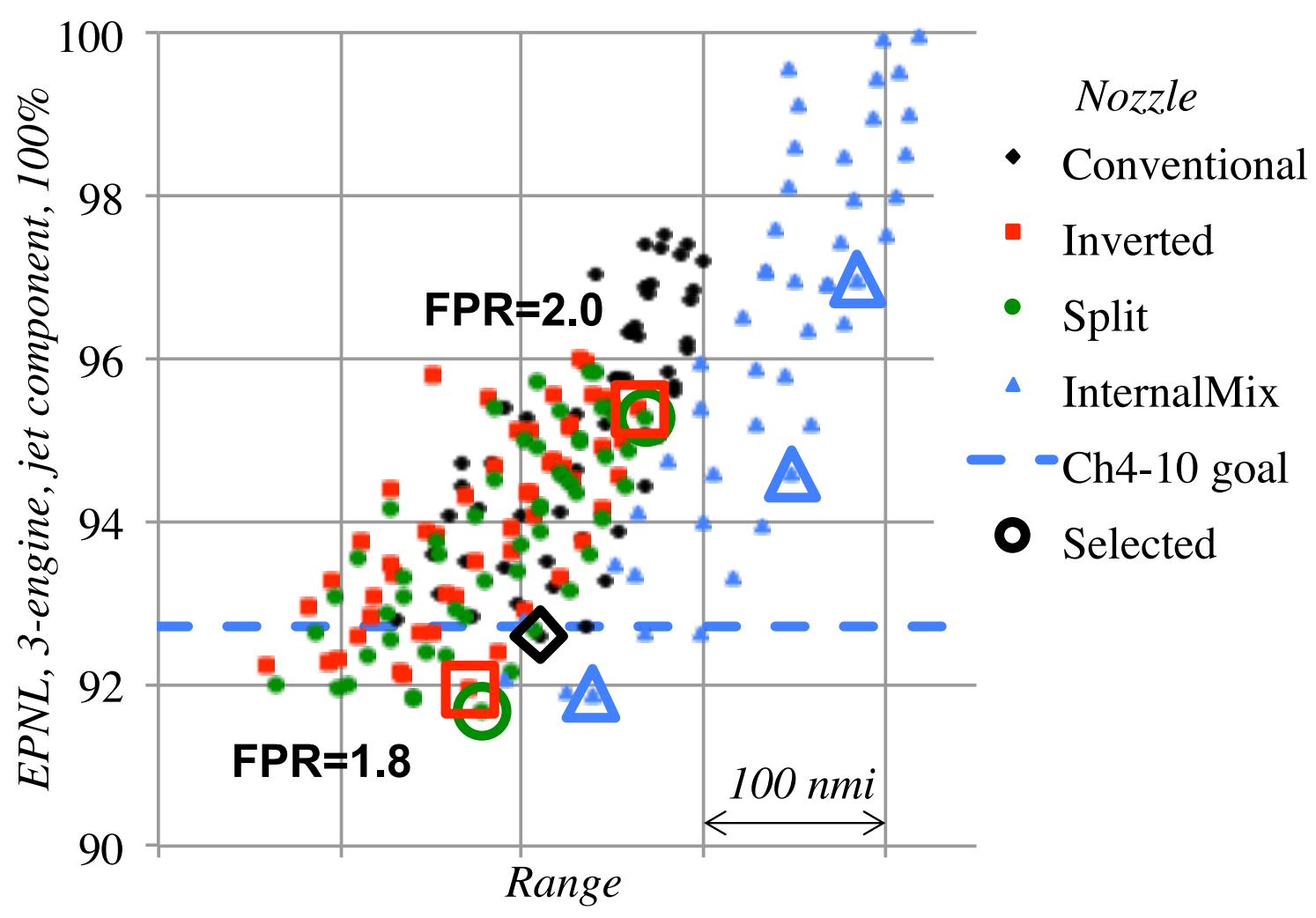




\section{Nozzle Types Selected for Validation}

- Four types of nozzles performed well acoustically in isolated nozzle testing were chosen for validation testing

- Nozzle hardware dictated model scale factors from 10-14.

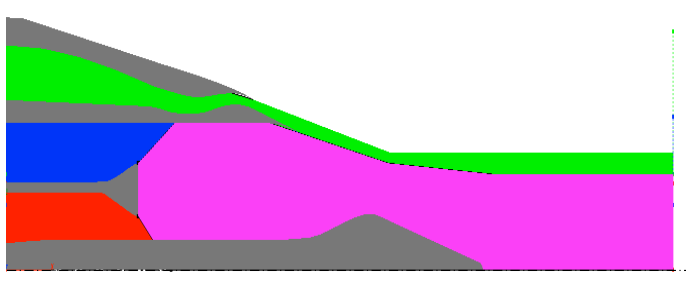

VCE, tip flow on outside (conventional velocity profile)

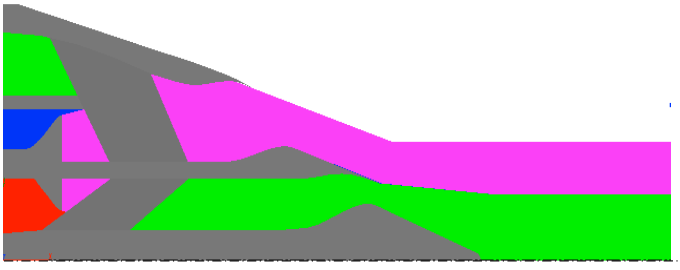

VCE, tip flow on inside (inverted velocity profile)

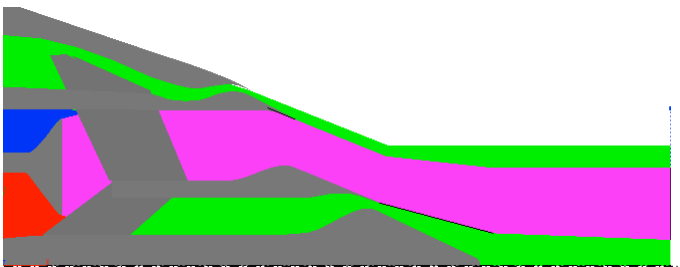

VCE, tip flow split

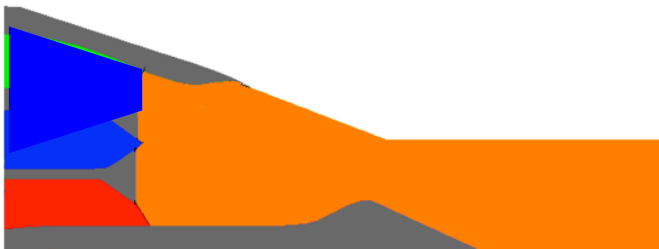

Mixed Flow Turbofan

Engine (internally

mixed) 


\section{Planform Representation of LM1044}

- Testing of isolated nozzles for noise well-established at GRC.

- Testing of installed propulsion not as common anywhere.

- Full aircraft cannot fit inside wind tunnel with adequate scale factor.

- How to properly represent installed propulsion for acoustic testing?

- How much airframe must be represented?

- How to compensate for differences in nacelle and rig sizes?

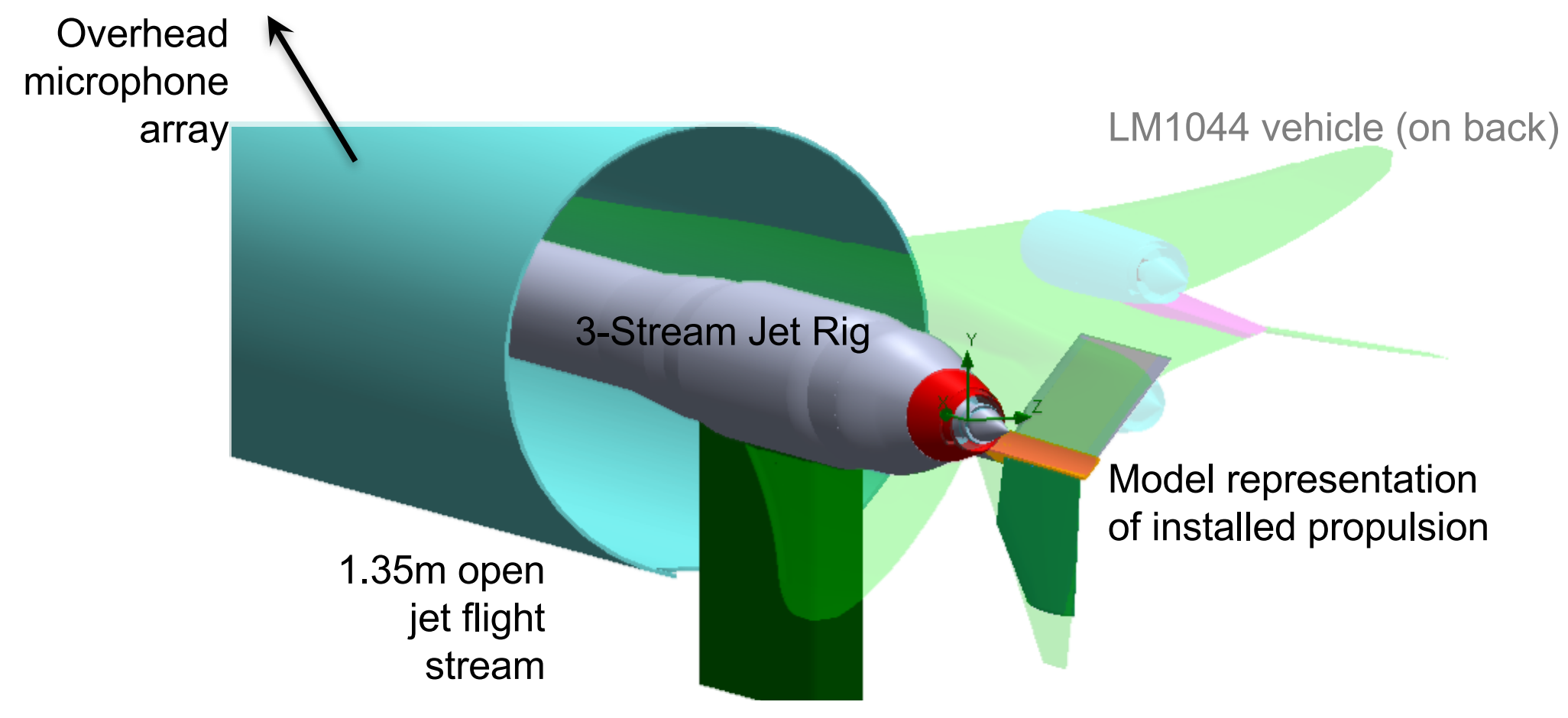




\section{NASA Glenn Aero-Acoustic Propulsion Lab}

\section{High-Flow Jet Exit Rig}

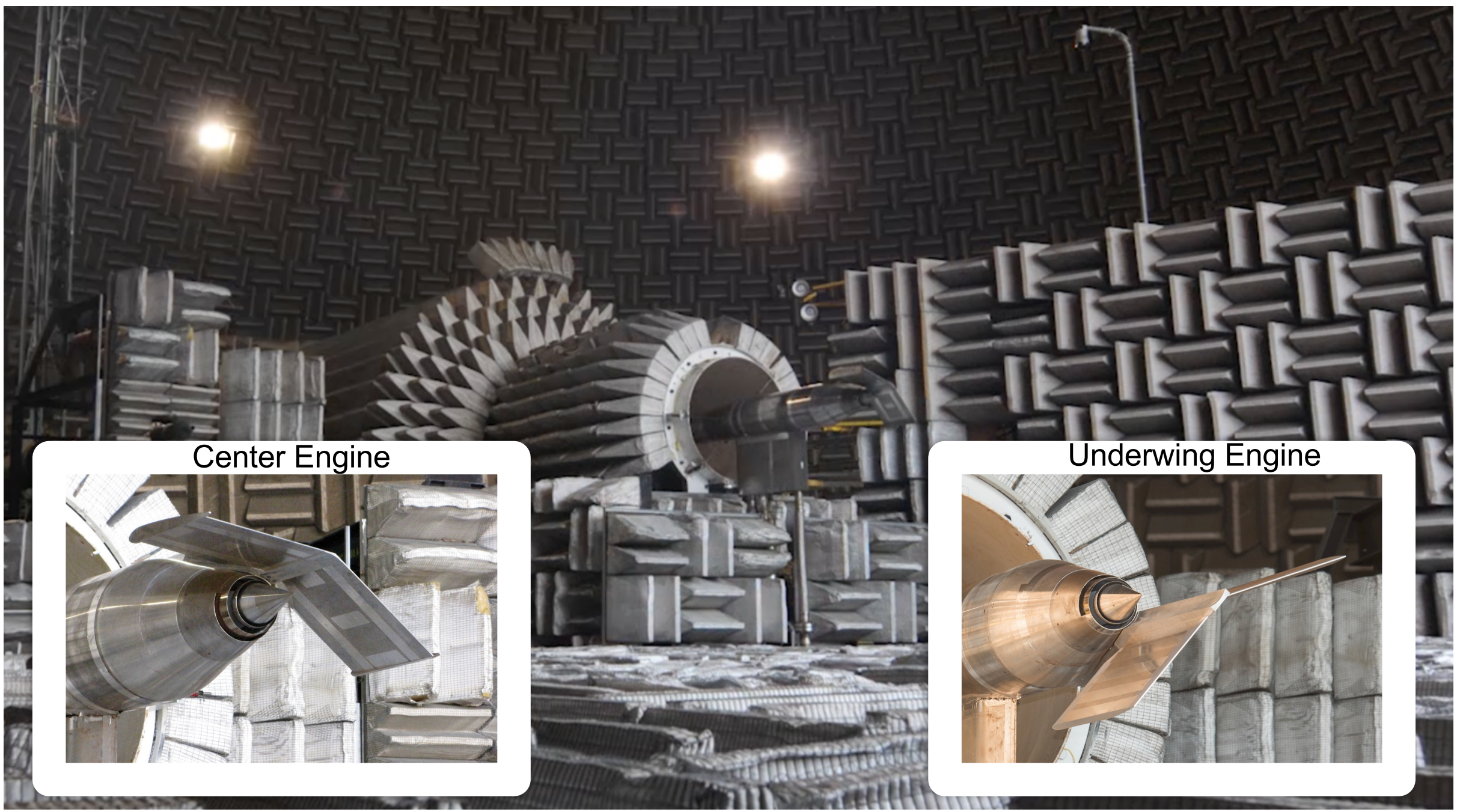




\section{Instrumentation}

$\bullet$

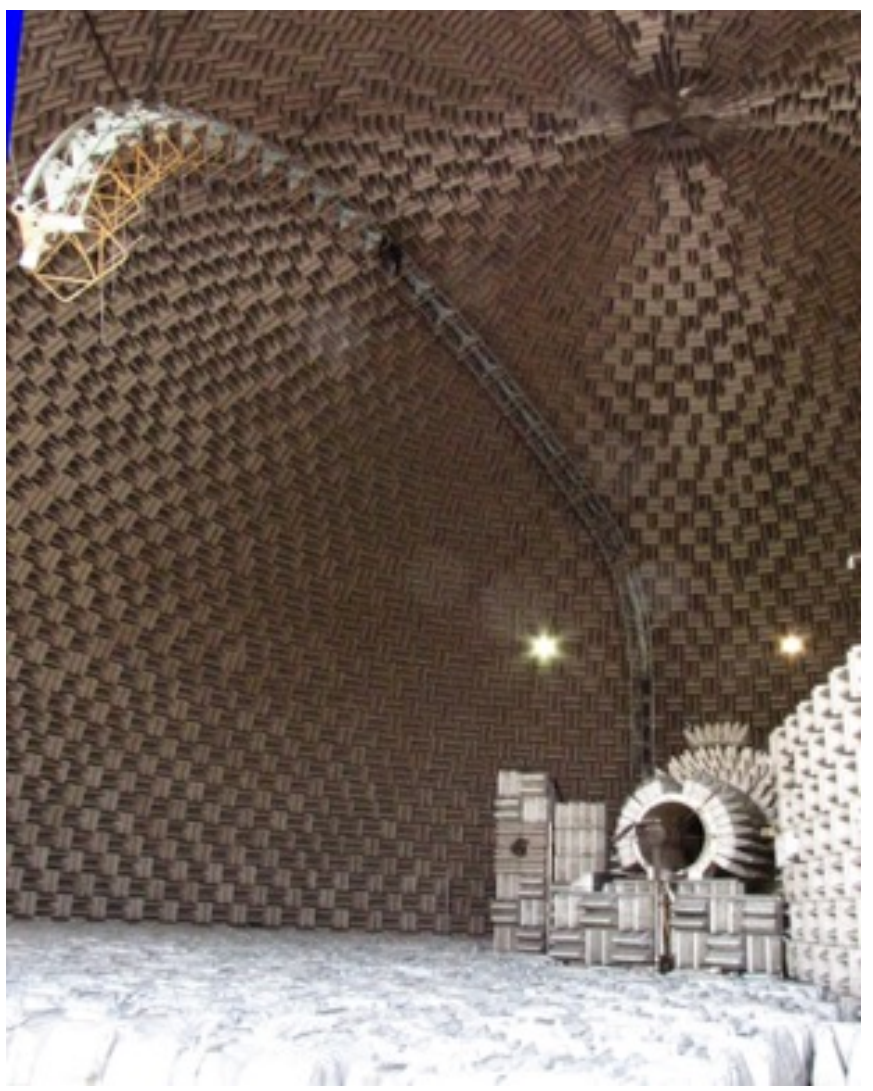

Far-field acoustics 24 B\&K 1/4" microphones $\sim 14 \mathrm{~m}$ arc polar array

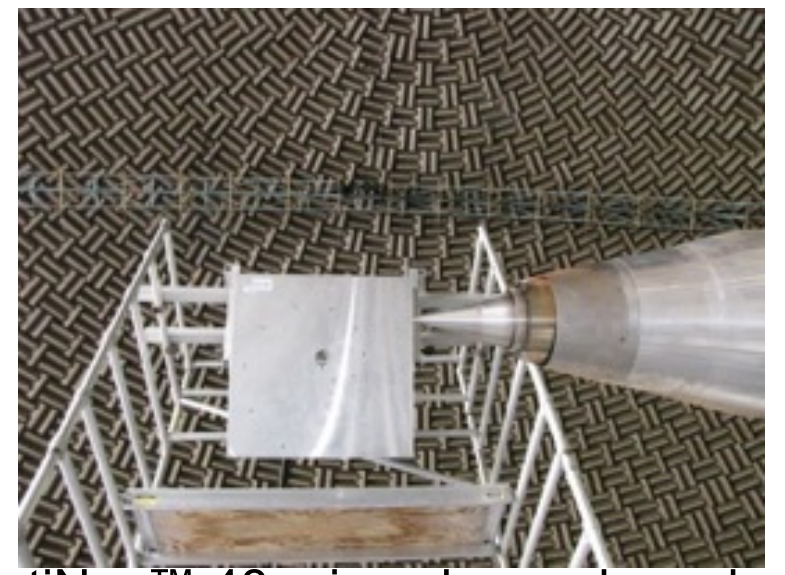

OptiNav TM 48-microphone phased array $300 \mathrm{~Hz}-30 \mathrm{kHz}$

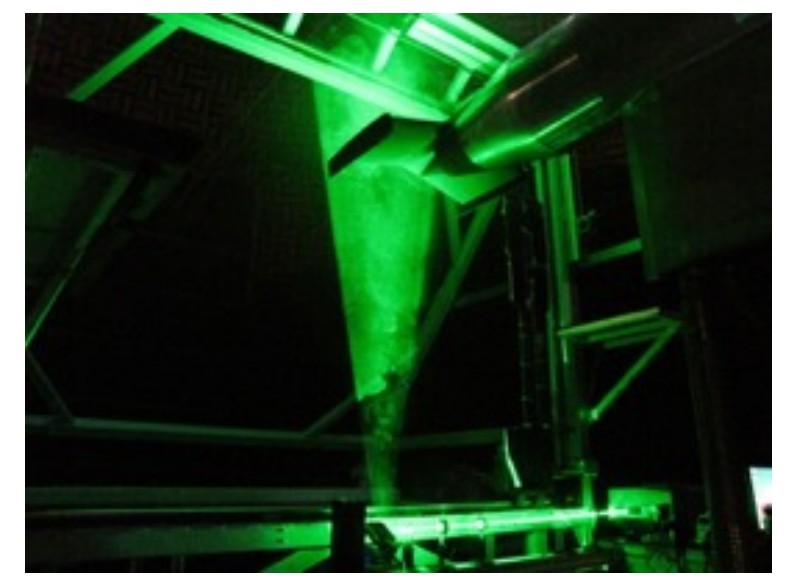

PIV: 1.3mm measurement resolution

Streamwise: 2-component, $1.8 \times 0.58 \mathrm{~m}$ FoV Cross-stream: 3 -component, $0.39 \times 0.32 \mathrm{~m}$ FoV 


\section{Planform Adequacy for Flow Similitude}

- Jet rig is significantly larger than engine nacelle. Is flow around nozzle same as vehicle?

- Extending upstream end of planform produced separation zone at juncture.

- Truncated planform upstream before meeting rig, flow not separated; similar boundary layer around perimeter. Planform adequate aerodynamically.
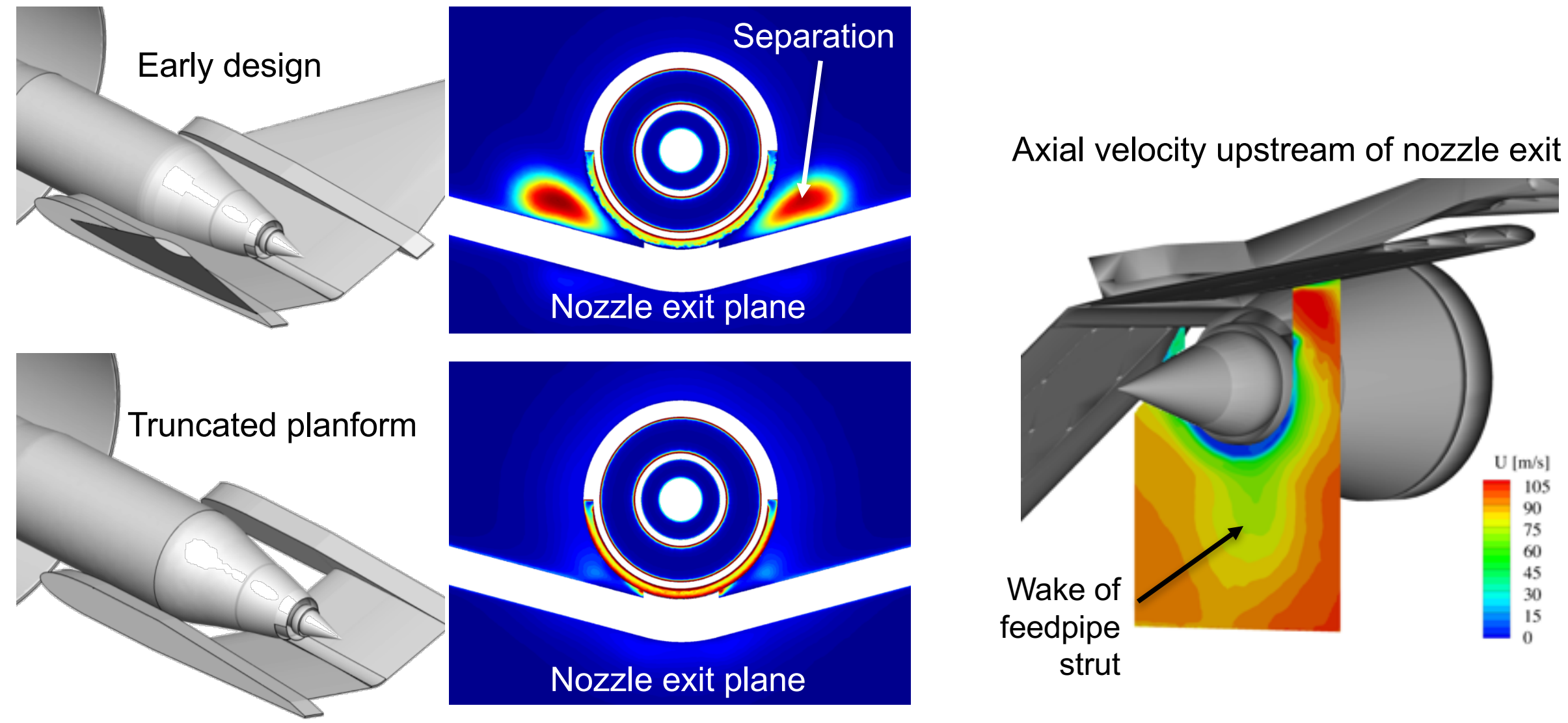

*Bridges, J. E., Podboy, G. G., and Brown, C. A., “Testing Installed Propulsion For Shielded Exhaust Configurations,” AIAA $2016-3042$. 


\section{Planform Adequacy for Acoustic Similitude}

- Model representation of airframe is truncated planform. Does it represent full shielding/reflection of full airframe?

- Phased array measures 'acoustic leakage' (both beam-forming error and diffraction from truncated planform edges) that contributes to upstream strength.

- Noise from upstream of trailing edge insignificant compared to total. Sound not leaking around planform's truncated edges. Planform adequate acoustically.
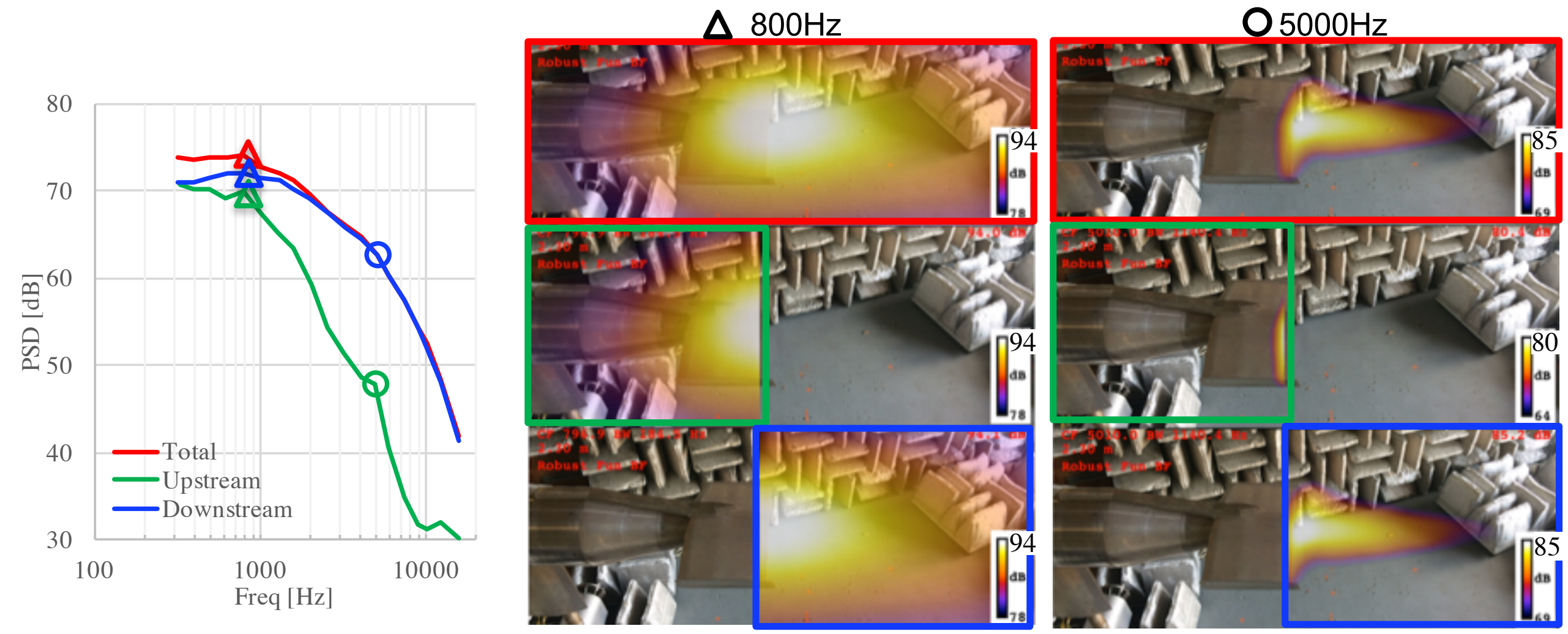

Bridges, J. E., Podboy, G. G., and Brown, C. A., “Testing Installed Propulsion For Shielded Exhaust Configurations,” AIAA $2016-3042$. 


\section{Effect of Flight on Noise (Flight Exponent)}

- LM 1044 was designed to be flown fast over observer $\left(M_{f}=0.38\right)$

- Background too loud for good model data. Extrapolate in $M_{f}$ !

- Flight effect is classically captured by flight exponent $k$ :

$$
\operatorname{PSD}\left(M_{f 1}\right)+k^{*} 10 \log 10\left(V_{j}-V_{\infty 1}\right)=P S D\left(M_{f 2}\right)+k^{*} 10 \log 10\left(V_{j^{-}}-V_{\infty 2}\right)
$$

- Used $M_{f}=0.0,0.25,0.30,0.35$ data to find good model for $k$ using Bare nozzle. Confirmed on installed cases.

- $\quad k$ is a strong factor in freq and polar angle. Vishy \& Czech (2011) document a model $k$ (polar), which works well for JSI16 OASPL.
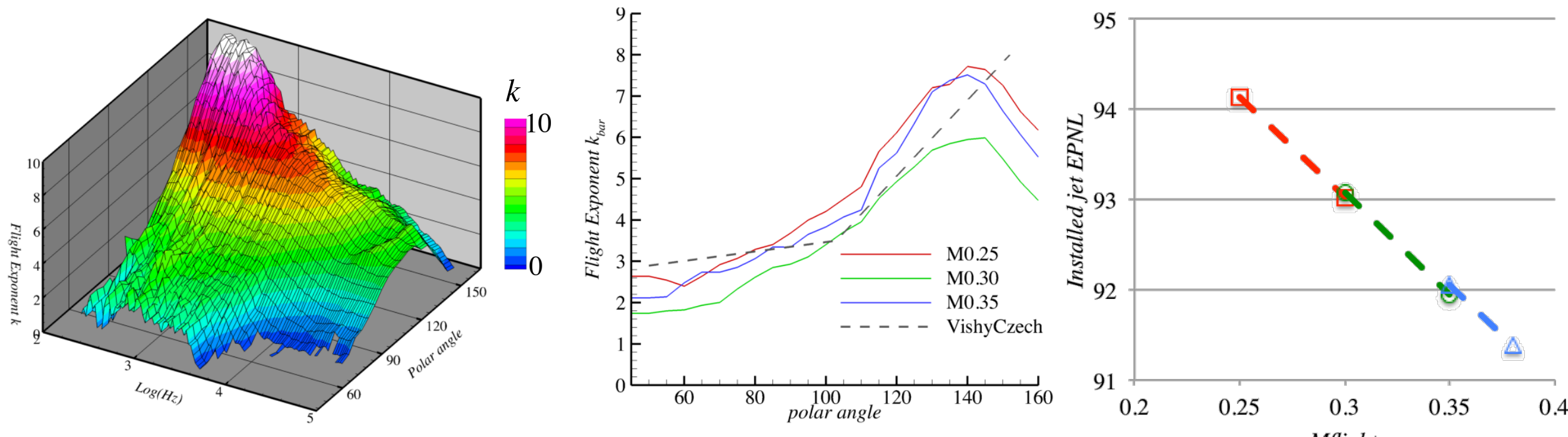

Viswanathan, K., and Czech, M. J., "Measurement and Modeling of Effect of Forward Flight on Jet Noise,” AIAA Journal, vol. 49, 2011 


\section{Effect of Flight on Jet Plume}

- Important to understanding of flight effect on shielding/reflection

- Unheated $M a=0.9$ single-stream jet vs flight speed $M_{f}$

- Mean and turbulent velocities acquired with PIV

- TKE strength reduces and plume stretches with increased flight speed.
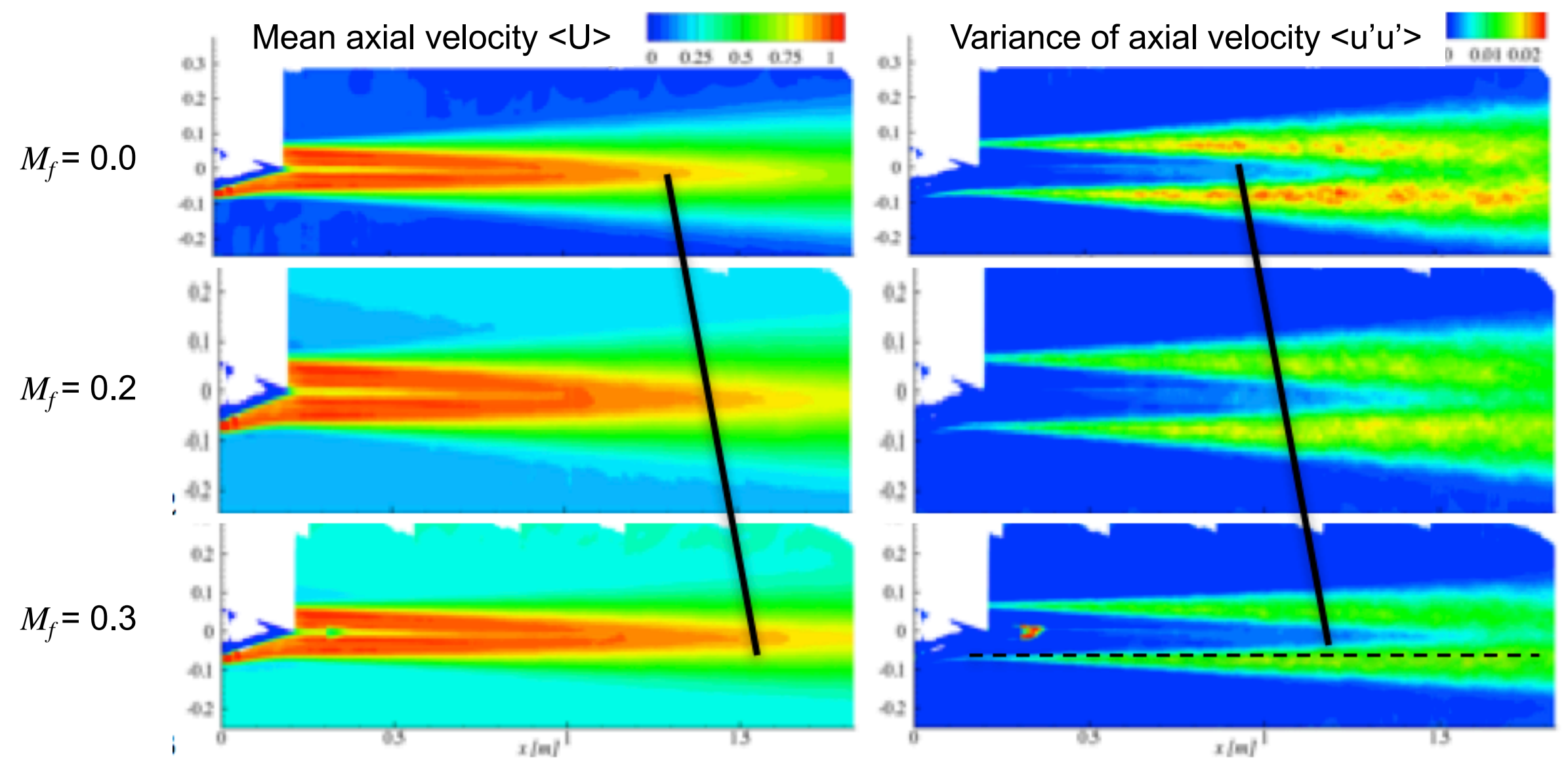


\section{Effect of Flight on Source Distributions}

- Source distributions measured using phased array

- Unheated $M a=0.9$ single-stream jet vs flight speed $M_{f}$

- Source strength at end of potential core reduced by increase in flight speed.

- Correlates with strong effect on peak noise

- Correlates with reduction in TKE

- Source strength near nozzle not affected much.

- Correlates to small effect on high frequencies

- No correlation with TKE

- Nozzle/plug surface causing dipole behavior?

- Flight speed does not stretch source region!

- Does not correlate with spatial shift of TKE

- ????

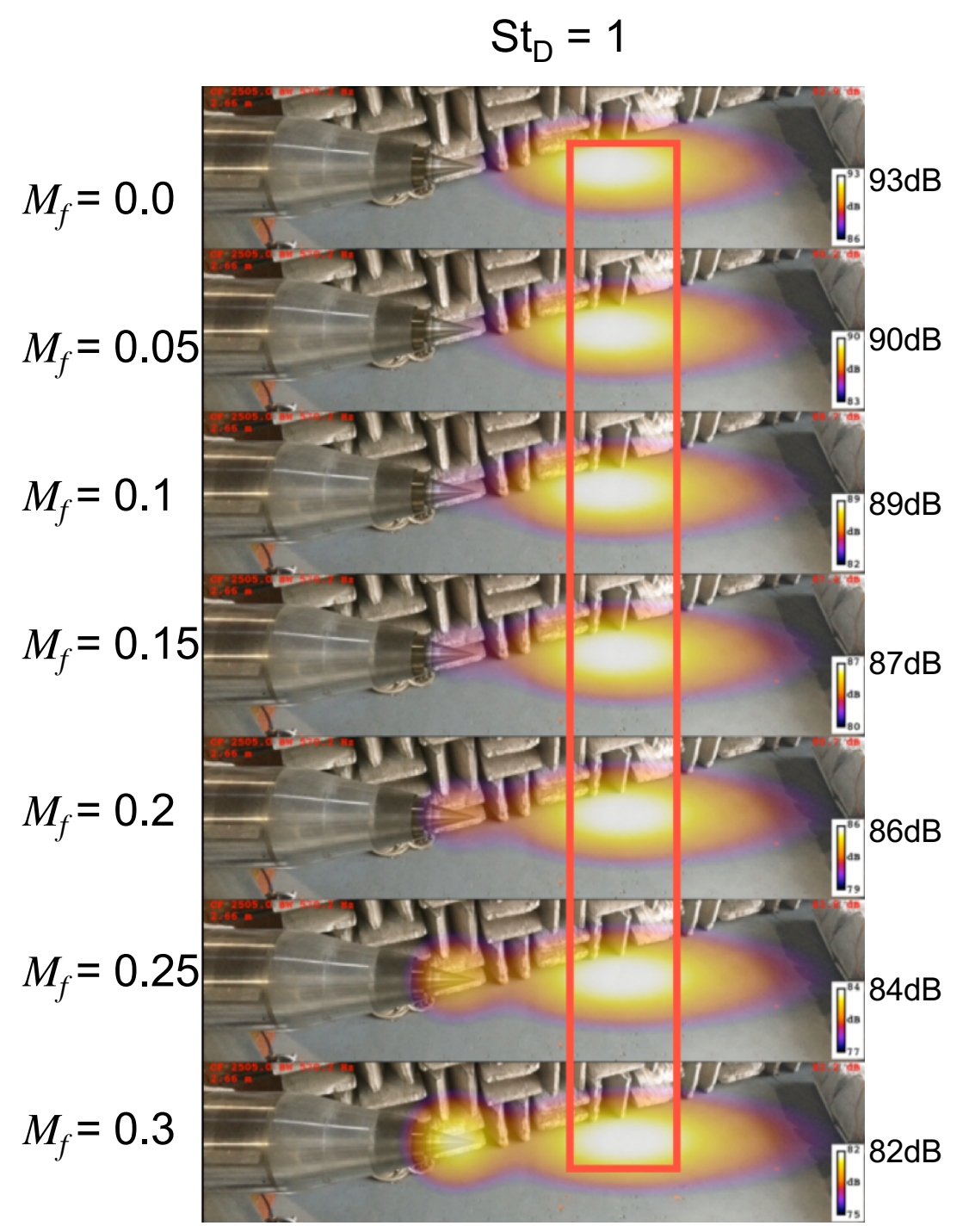




\section{Noise Contribution by Installation Location}

- Contributions from each engine separated for illustration

(Combined at spectral level for actual computation)

- As seen in annoyance (volume is EPNL)
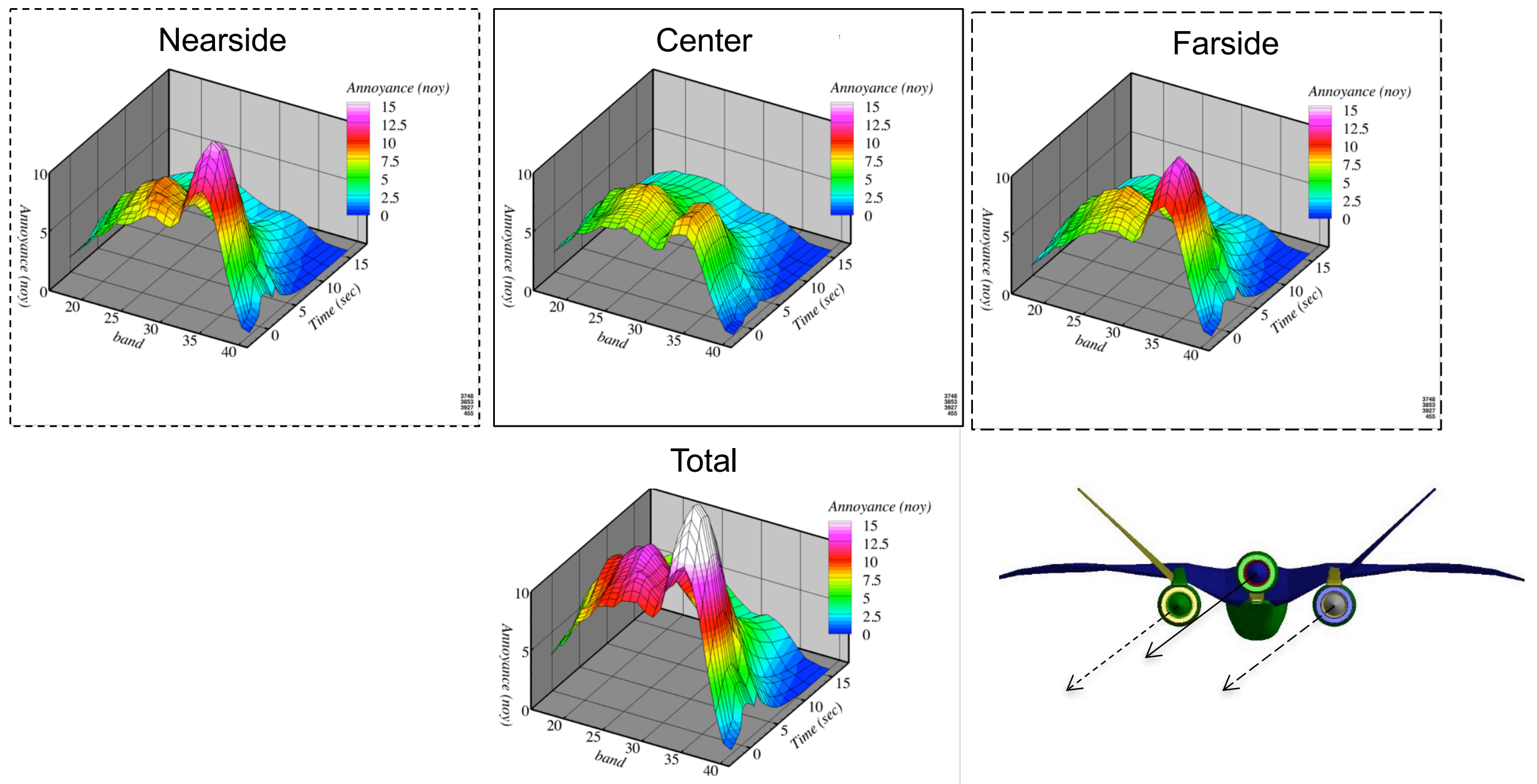


\section{Installation Effect-Mount Location}

- EPNL for each engine/nozzle as seen by Lateral observer

- Grouped by engine/nozzle (plot) and cycle (color)
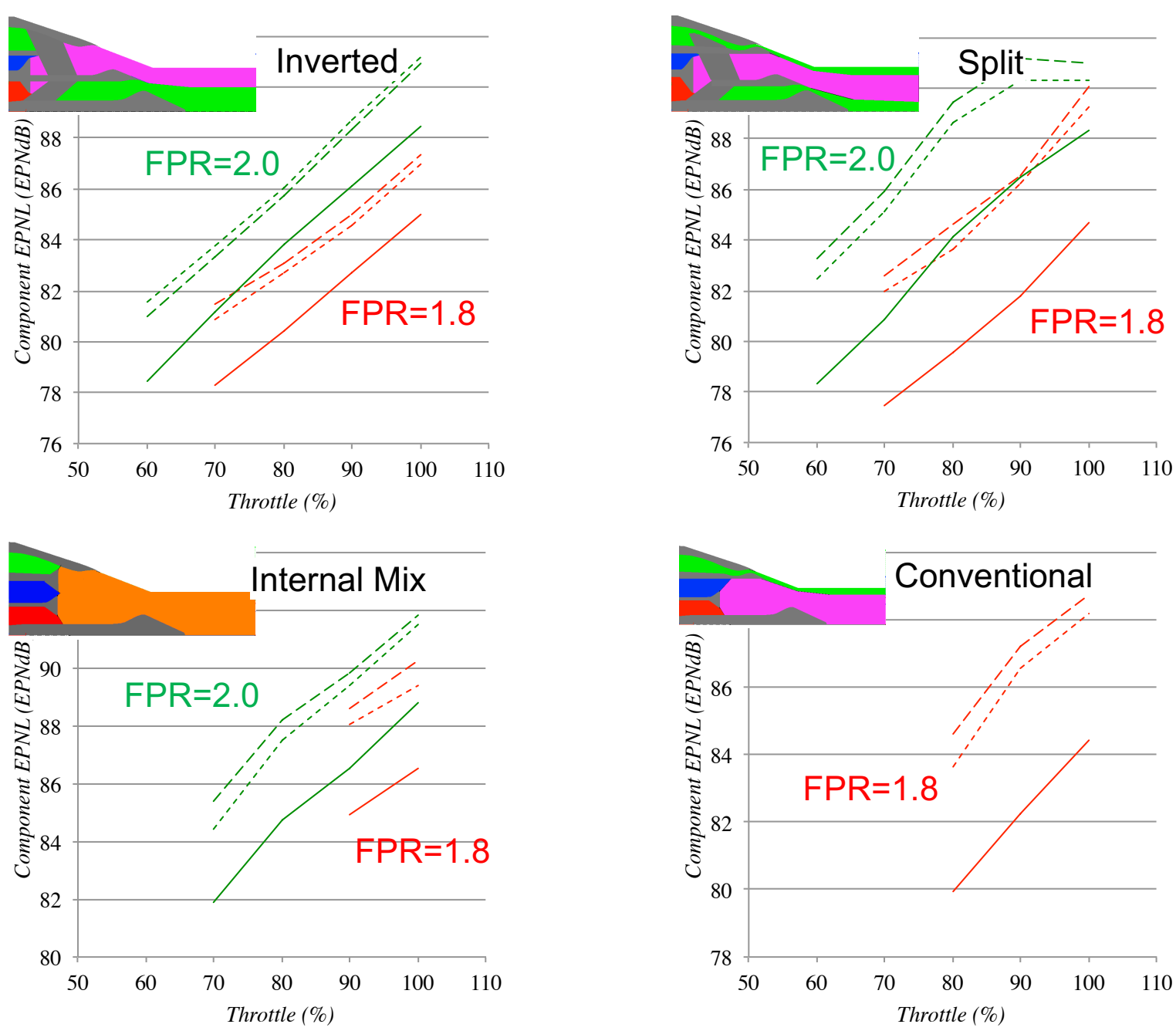


\section{Integrated Propulsion Exhaust Noise}

- Three-engines, lateral observer, 1000' level flight at $\mathrm{M}_{\infty}=0.38$

- Nozzle type in color, FPR in symbol fill
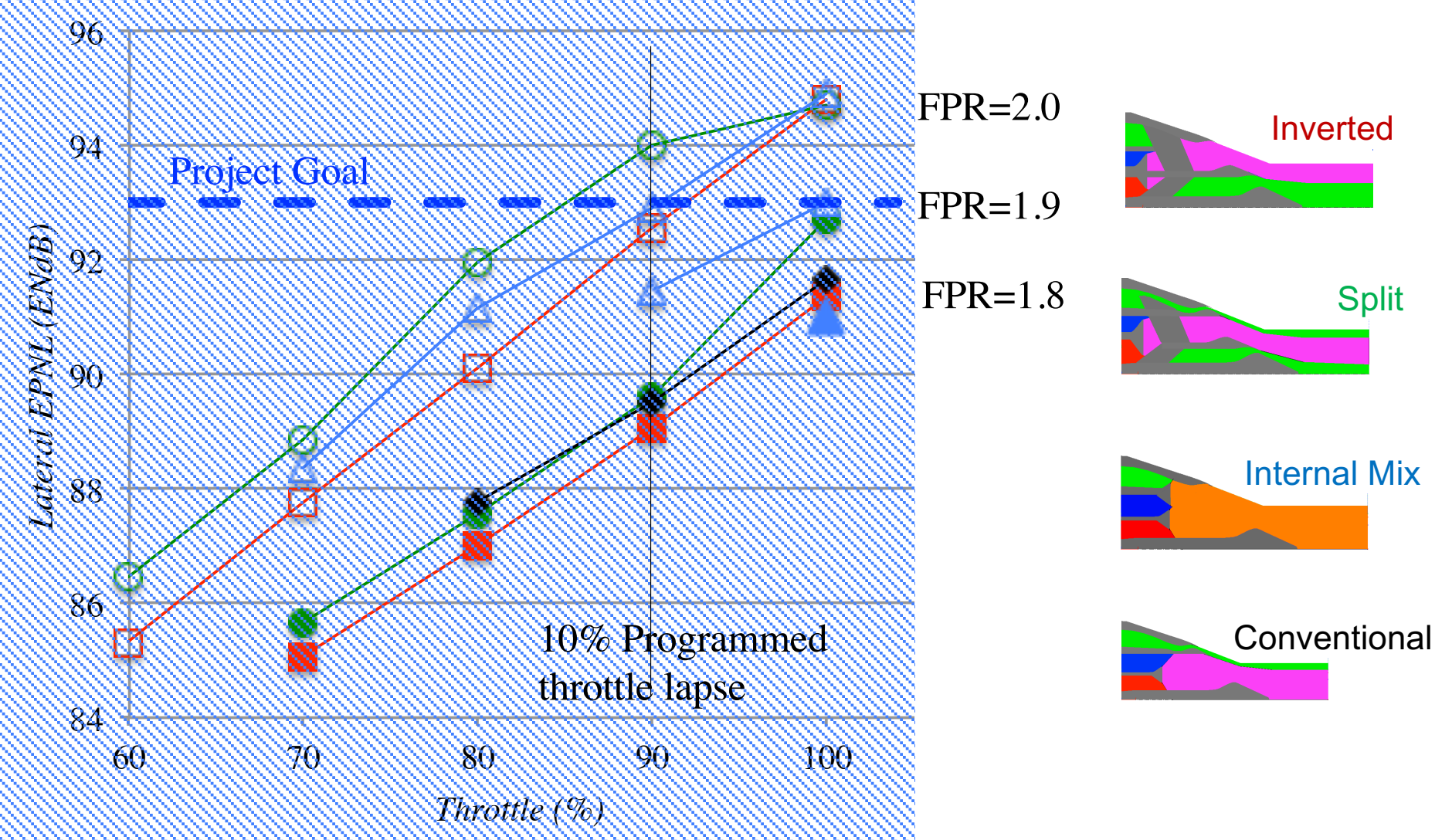


\section{Comparisons of Design Predictions and Data}

- Demonstration test Data plotted against design Predictions.

- As predicted, several designs produced noise that meet Noise Goal.

- Predictions match data within $+1 \mathrm{EPNdB}$.

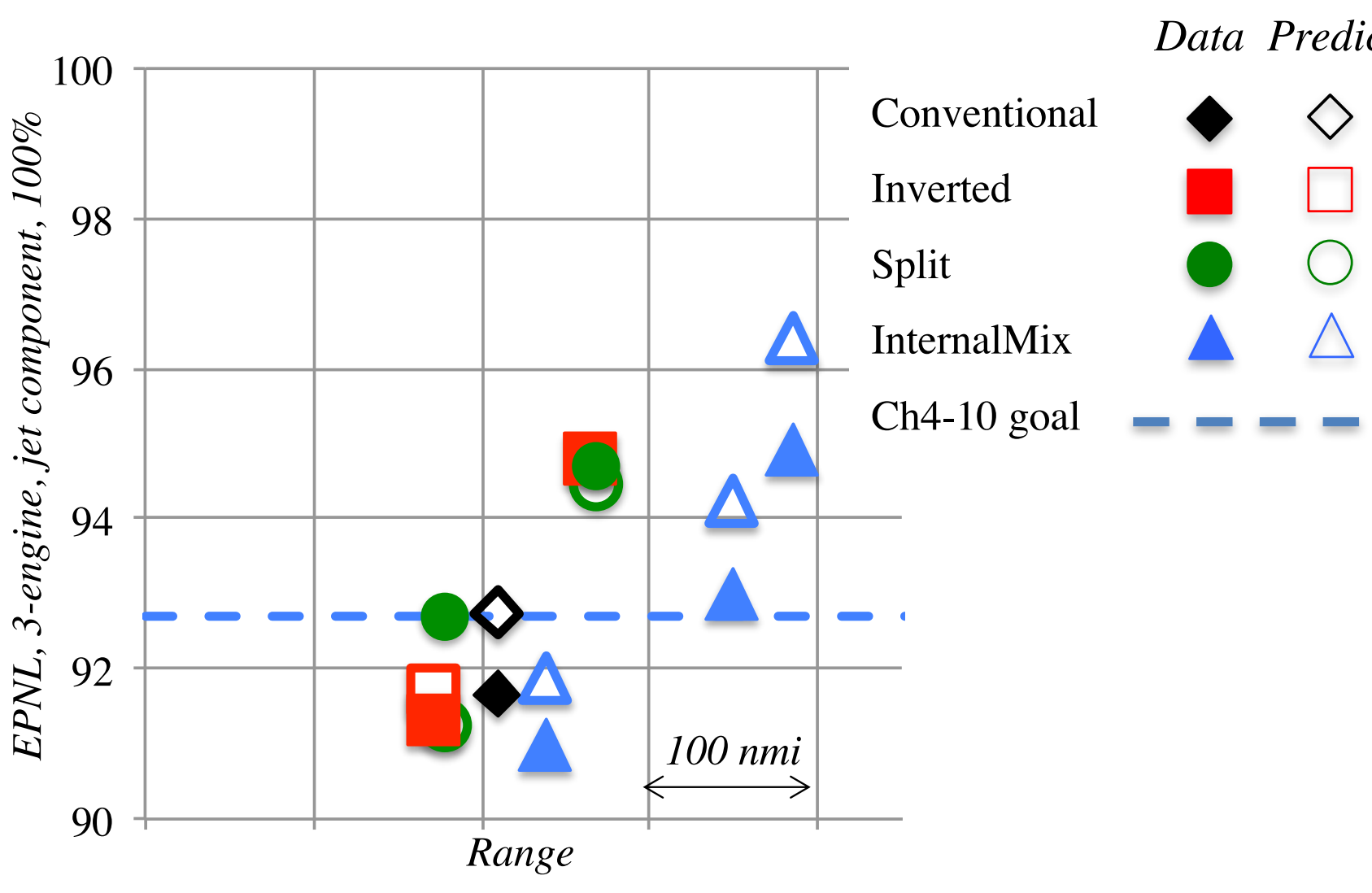




\section{Summary}

- Test designed to validate system studies of engine/nozzle designs to allow $\mathrm{N}+2$ supersonic aircraft to meet aircraft LTO noise regulations.

- Model-scale test representations of installed propulsion designed and built.

- Assumptions of representations validated.

- Flight effects on installed exhaust noise explored

- Flight effect model for uninstalled jet found acceptable for installed propulsion

- Flight effect on plume statistics documented

- Flight effect on noise source distributions documented (with questions!)

- Impact of installation location documented.

- Variations with nozzle type noted.

- Lateral certification noise EPNL calculated for multiple engines and nozzles.

- System-level noise prediction tools, and study findings, were confirmed. 


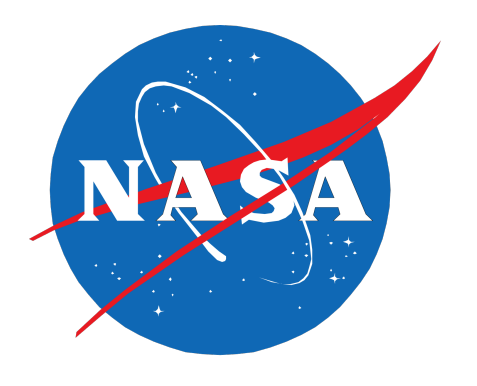

james.e.bridges@nasa.gov 